\title{
INVESTMENT CASTING OF SUPERALLOYS
}

\author{
John Hockin \\ Hockin A.ssociates \\ Chicago
}

\section{INTRODUCTION}

The basic process of investment casting used for the manufacture of complex shapes in difficult to machine alloys is a development of the ancient lost wax process used for producing metal replicas of wax sculptures.

In the basic process patterns usually of wax are injection molded, a ceramic monolithic mold is built up around these patterns by a series of dip coatings and after the mold has hardened, the wax pattern is removed from the shell mold.

Residual organic material is burned out and the mold heated to temperatures in the range of $12^{\circ} \mathrm{F}$ to $2000^{\circ} \mathrm{F}$ and metal poured into the cavity.

After the metal has solidified and cooled, the mold is broken away and castings processed through normal finishing operations.

Unique properties are obtained with the lost wax process and are primarily concerned with close dimensional tolerances due to a single monolithic mold and superior metallurgical characteristics caused by the use of hot molds.

The basic process is an expensive process and the major cost difference between investment casting and other casting methods lies in the necessity to produce expendable patterns and make individual molds from these.

Reductions in the cost of making investment castings throughout the years have been accomplished and one of the major reductions in the labor cost is accomplished by processing multiple components in the form of a tree or cluster. The reductions in the cost of making the shell mold and casting in many cases, however, can be offset by the cost of assembling the components into the clusters to provide multi-component handling and also the cost of breaking this down to cover the individual components.

\section{BLADES AND VANES}

The major field for investment casting of superalloys is concerned with the manufacture of blades and vanes. This has become a specialized field of investment casting technology requiring different processing techniques to insure the high metallurgical quality in today's gas turbine engines.

The progress over the years in the complexity and integrity of investment castings has given a continual improvement in capability of the process. 


\section{Solid Blades and Vanes}

The earliest application of investment casting was primarily in the manufacture of airfoil shapes such as blades and vanes used in the turbine engine. Today's technology allows these to be produced with scrap rates of less than $10 \%$ in the majority of cases.

\section{Controlled Grain Size}

The first major move to control the quality of investment cast blades and vanes was the incorporation of controlled grain size. This control of grain size in the casting operation was accomplished by control of the processing parameters such as casting temperatures, together with the use of grain nucleants in the facc of the mold.

Although the exact mechanism of the nucleation is still not understood, early theories as to mechanical nucleation sites, thermal conductivity nucleation, etc. have shown to be not the mechanism of nucleation.

The common nucleants used today include salts of cobalt and nickel such as the silicates, aluminates, etc.

Early work using the oxides of elements such as nickel, cobalt and iron are lcss common today duc to interference and the solubility of these components in constituents of the pattern materials and resulting problems due to the normal processing techniques.

What little work that has been done to understand the mechanism of nucleation indicates a large absorption of heat by the nucleant resulting in an increase in the cooling rate during solidification.

Explanations for this heat absorption indicate either the presence of endothermic reactions or the reduction and solution of the nucleating metallic particles.

The system is out of balance as far as the heat transfer is concerned due to the large heat absorption during the nucleation.

Much work has been done on the control of the grain on the outside of castings but very little with regard to the internal grain structure of cast blades and vanes.

The major use of controlled grain size today is a measure of the consistency of the process rather than dramatic effects on the mechanical properties. Further discussion of the effects of grain size on mechanical properties is covered in later sections.

\section{Air Cooled Components}

The next major step forward in the production of investment cast blades and vanes was the development of the processing capability to produce complex internal 
passages for improved thermal properties of the components and the ability for turbine inlet temperatures to be increased radically with the use of air cooling.

Due to the high temperature property limitations of the ceramic core systems based on silica, the capability for the production of cooled components has been accomplished at large increase in cost due to high scrap rates and with the complex cored components today, scrap rates as high as $75 \%$ are not unknown on production parts.

The basic system of forming ceramic cores from a silica system is used due to a compromise in the mechanical properties and the ability to remove by leaching the ceramic cores from the castings.

\section{Controlled Mechanical Properties}

The next major step in the investment casting processing capability has been in the area of controlled mechanical properties. In both the nickel and cobalt-base alloy systems, the properties produced in cast components are dependent on the alloy composition and also the cooling rates during and after solidification.

In the supersaturated nickel-base casting alloy field, many of the mechanical properties are determined in the casting process and are not subject to the improvements by heat treatment.

Progress, however, in this field has been severely hampered by the fact that destructive testing is neccssary to dctermine these properties and mechanical limitations on the size of test bars does not allow adequate evaluation of the variations in mechanical properties throughout components.

The state-of-the-art today allows the properties of components to be measured at a particular point in the casting only.

One, two or ten tests from a production lot of castings does not allow the full integrity of the process to be evaluated without excessively large safety factors being applied.

\section{RECENT AND CURRENT PROBLEMS}

As the demands for higher integrity, longer life turbine engines has increascd the importance of many aspects of the variables of investment casting has also incrcascd.

Wilh every increase in capability, there come new problems.

With economic pressures being applied and the difficulties of engineering controls and methods of determining acceptability, problems have been encountered. 


\section{Trace Elements}

Due to the necessity of reducing costs and using more available sources of materials, substantial problems have been encountered with trace elements hitherto before not even measurable creating problems to the level of engine failures.

Many detrimental trace elements such as lead. bismuth, etc. have been identified, but much more work is still required to determine the cffects of residual elements in the parts per million category as far as the ones that are beneficial and the ones that are detrimental.

Obviously not all impurities are detrimental and if controls of all residual elements could be established today, then some of the mechanical properties could be lost.

\section{Intergranular Attack}

Major problems in intergranular attack in the removal of ceramic cores from air cooled hardware have been experienced.

Requirements to limit intergranular attack below . 0004" are common today and normal methods of removal of the ceramic cores can cause intergranular attack on nickel or cobalt-base alloys of 10 to 20 times this level.

Problems due to metal mold reaction also enter into this area.

It is not unusual for metal core reactions with the silica system to be as high as $50 \%$ of the total allowable intergranular attack.

The normal methods for removal of the ceramic cores include the use of potassium hydroxide solutions at temperatures of up to $600^{\circ} \mathrm{F}$ and pressures up to 1000 psi. Residual trace elements such as chlorides in the potassium hydroxide solutions can flux protective oxide layers resulting in catastrophic intergranular attack. Control of impurities and limitations on time and temperatures are necessary to control this intergranular attack.

Newer techniques of using potassium hydroxide solutions at atmospheric pressure at their boiling point for times of 100 to 150 hours have overcome many of the intergranular attack problems but still present problems as far as casting production is concerned.

\section{Control of Mechanical Properties}

Work done over the recent years to understand the effects of cooling rates on the mechanical properties of the cast nickel and cobalt-base alloys has led to an understanding of the variations that can be encountered but not to complete control.

Efforts to control the casting parameters do not necessarily control cooling rates as difficult to measure properties such as the thermal characteristics of the 
mold material radically change the cooling rates during and after solidification. In order to get controlled or consistent mechanical properties, therefore, it is not always advisable to cast each mold at the same metal and mold temperatures, but adjustments should be made to give controlled cooling and solidification rates depending on the thermal characteristics of the shell.

The effects of grain size are really not known as far as their effect on mechanical properties in spite of much work and literature published. The major reason for this is that work to evaluate changes in the grain size have always been accomplished with changes in the casting parameters to accomplish the difference in grain size which changes the cooling rates. The grain size is a manifestation of the cooling rate throughout a small portion of the cooling curve, namely during solidification.

Cooling rates from initial solidification down to temperatures as low as $1850^{\circ} \mathrm{F}$ can effect mechanical properties and it is possible to change the grain size radically without changing the high temperature properties. Similarly; it is possible to change the high temperature mechanical properties radically without changing grain size.

The casting process is not yet sufficiently well controlled for the effects of grain size changes only to be studied. Changes in grain size are almost always accomplished by changing overall cooling rates and consequently many changes are evaluated with grain size being used as a manifestation of this.

Similarly, measurements of dendrite arm spacing, etc. can be related to cooling rates but only over a small temperature range in the cooling curve.

\section{Hafnium in Nickel-Base Alloys}

Recent developments in the nickel-base alloy field with the use of hafnium to provide more consistent mechanical properties from turbine components have led to problems.

Hafnium oxide has some unique qualities not normally experienced in the oxides of normal superalloy constituents, the major one being the density being greater than the metal.

Problems with hafnium oxide inclusions in nickel-base alloys is a very real and possible problem.

Hafnium oxide is seen, basically, in three different stages. The first where major hafnium oxide inclusions are present may bc dctccted by non-destructive tests normally employed on cast components such as $x$-ray, etc. These are easily determined due to their density.

The second stage of hafnium oxide is where platelets of hafnium oxide can be dispersed throughout the microstructure and these fine oxide inclusions are not detectable by normal non-destructive tests carried out on production castings. 
The third form of hafnium oxide which is observed as a very fine Chinese script-like precipitate is normally not considered detrimental.

Control of melting pressures hot leak-up rates and hafnium - ceramic reactions such as with silica are necessary to prevent hafnium oxide inclusions in castings.

Ilafnium oxide can be formed in the master melt operation and consequently dispersed throughout the remelt stock or during the casting operation.

\section{Microshrinkage}

Many forms of microshrinkage can be present in superalloy castings.

The most prevalent and recent problems, however, have been created due to the changing micro-chemistry of nickel-base alloys.

Straight mechanical shrinkage can be caused by the presence of eutectic gamma prime present in the supersaturated cast alloys.

This is causcd by the eutectic gamma prime being the last constituent to solidify and being surrounded by a solid matrix and the volume changed during solidification of the eutectic gamma prime creating microshrinkage or voids.

Complex reactions with the addition of many of the constituents of the nickelbase alloys result in indirect changes in the micro-chemistry.

For example, the addition of hafnium to nickel-base alloys radically changes the composition of the eutectic gamma prime. This is accomplished by the substitution of hafnium in the $\mathrm{MC}$ carbides for titanium and rirconium resulting in a higher titanium and zirconium content in the gamma prime than normal.

Improvements in the mechanical properties of the nickel-base superalloys by the addition of hafnium, therefore, has to take into consideration the composition of the gamma prime and in alloys containing maximized titanium contents, the addition of hafnium is sufficienl lu produce a higher or non-optimum titanium content in the gamma prime resulting in a drop in properties. Compensating reductions in titanium and zirconium to maintain the equivalent gamma prime chemistry, however, can result in substantial improvements.

In the control of microshrinkage, therefore, the composition of the eutectic gamma prime, its liquation temperature and the effects of the constituents will radically change the incidence of microshrinkage.

In general, one can say that elements that increase the melting point of eutectic gamma prime will be beneficial for microshrinkage control as opposed to those elements that decrease the melting point should be detrimental.

In the early work done on the additions of hafnium conclusions were drawn 
that hafnium promoted the formation of microshrinkage, when in fact the increase in titanium and zirconium were basically responsible for the increase in microshrinkage.

Adjustments of very small amounts of titanium, for example, in the hafnium nickel alloys can result in a radical change in microshrinkage.

The evaluation of microshrinkage requires quantitative measurements and if this is studied in alloy systems such as B1900, reductions in the range of. $3 \%$ titanium and control of zirconium can rcsult in reductions in microshrinkage from normal B1900 to the hafnium/titanium/zirconium modified alloy to approximately $1 / 4$ of the volume of microshrinkage.

\section{CONTROL OF MECHANICAL PROPERTIE:S}

Significant increases in the temperature capabilities of today's cast alloys can be accomplished by control of the mechanical properties during the casting operation.

The Effects of Master Melt Alloy

The master alloy and the manufacturing methods used can significantly affect the final properties of many of the cast alloys.

With the advent of the higher strength cast alloys, the processing of the master alloy becomes significantly more critical and control in this area is becoming increasingly more recognized.

Not only increases in the degree of vacuum refining but control of the metal. crucible reactions are necessary and are particularly important in the case of the newer, higher titanium alloys.

The Use of Hafnium

Control of mechanical properties through the use of hafnium in the nickelbase alloys has provided a major step forward. In many cases of alloys modified with hafnium, the effect of cooling rates is reduced to the extent that good and consistent properties can be obtained almost independent of the section thickness.

In the case of alloys such as $713 \mathrm{LC}$ modified with hafnium, ductility can be maintained in the 10 to $15 \%$ range at room temperature with sections from less than $1 / 8^{\prime \prime}$ to over $6 "$.

In most cases the use of hafnium does not improve the alloy characteristics, but does allow consistent properties at the higher end of the normal alloy scatter band to be maintained.

Cooling Rates and Solidification

Control of cooling rates and solidification is necessary before control of 
mechanical properties can be achieved.

In the case of airfoil shapes, however, due to the geometry normal cooling of castings results in substantial variations in cooling rates throughout the section and results in significant variations in mechanical properties.

\section{Directional Solidification}

The use of directional solidification to overcome many of the problems of lack of solidification control with conventional castings is a production process.

Considerable improvements in the economics can be anticipated but problems associated with heat transfer to improve the control of the solidification rate are necessary along with improvements in the ceramic systems.

The requirements in the directional solidification system for the ceramics are different than conventional casting and use of high thermal expansion materials for cores can substantially reduce the thermal stresses during the solidification process.

Overcoming the inefficiency of solid/solid interface heat transfer using chill plates can result in significant improvements in the transfer and the directional solidification process.

\section{FUTURE NEEDS}

The most important requirement in the casting industry is the control of solidification and cooling.

With the exception of non-metallic inclusions, the majority of the causes of rejects and the large scatter band in the mechanical properties are associated with the solidification and cooling.

Automation will not provide consistent thermal characteristics of ceramic matcrials as control of the thermal charactcristics requirc control of spccific heat, density, thermal conductivity, etc. Systems allowing compensation for processing variables are necessary to get uniform solidification and cooling.

The casting process offers the capability of the most economical manufacturing technique. All manufacturing techniques require the liquid metal stage and improvements in the economic aspects of producing molds can result in major economic improvements.

Control of solidification and cooling in castings can allow non-uniform properties to be produced with non-uniformity being optimized for specific properties in different locations of components.

Understanding and control of crucible reactions such as magnesium oxide carbon reactions and the effect of elements such as chromium on the ductility of 
the nickel-base alloys require further understanding.

The variations in master melt properties and the variation in the casting affected properties must be understood and controlled.

With the control of solidification and cooling, which can effect the composition of the micro-constituents such as eutectic gamma prime, control of microshrinkage is also necessary. 